\title{
Inhibition of Caco-2 and HeLa Proliferation by Terminalia carpen- tariae C. T. White and Terminalia grandiflora Benth. Extracts: Iden- tification of Triterpenoid Components
}

\author{
Reece Courtney ${ }^{1,2}$, J. Sirdaarta ${ }^{1,2}$, A. White ${ }^{2}$, I. E. Cock ${ }^{1,2 *}$
}

Reece Courtney ${ }^{1,2}$, J. Sirdaarta ${ }^{1,2}$, A. White ${ }^{2}$, I. E. Cock ${ }^{1,2 *}$

'Environmental Futures Research Institute, Nathan Campus, Griffith University, 170 Kessels Rd, Nathan, Queensland 4111, AUSTRALIA.

${ }^{2} \mathrm{~S} c h$ ool of Natural Sciences, Nathan Campus, Griffith University, 170 Kessels Rd, Nathan, Queensland 4111, AUSTRALIA.

\section{Correspondence}

\section{Dr. I. E. Cock}

Environmental Futures Research Institute, Nathan Campus, Griffith University, 170 Kessels Rd, Nathan, Queensland 4111, AUSTRALIA.

School of Natural Sciences, Nathan Campus, Griffith University, 170 Kessels Rd, Nathan, Queensland 4111, AUSTRALIA.

Phone number: +61737357637

E-mail: I.Cock@griffith.edu.au

\section{History}

- Submission Date: 15-11-2016;

- Review completed: 05-01-2017.

- Accepted Date: 02-02-2017.

DOI : 10.5530/pj.2017.4.74

Article Available online http://www.phcogj.com/v9/i4

\section{Copyright}

(C) 2016 Phcog.Net. This is an openaccess article distributed under the terms of the Creative Commons Attribution 4.0 International license.

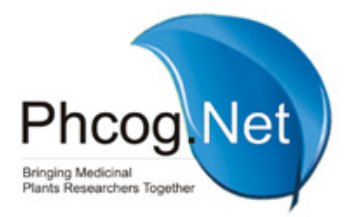

\begin{abstract}
Background: Terminalia spp. are characterised by their high antioxidant capacities and many have anticancer activity. This study examines the anti-proliferative activity of T. carpentariae leaf and T. grandiflora leaf, fruit and nut extracts against Caco-2 and HeLa carcinoma proliferation. Materials and Methods: Powdered T. carpentariae leaf and T. grandiflora leaf, fruit and nut were extracted and tested for anti-proliferative activity against Caco-2 and HeLa cancer cell lines using colorimetric cell proliferation assays. Toxicity was evaluated using an Artemia franciscana nauplii bioassay. The extract with the most potent anti-proliferative activity was examined using GCMS analysis and triterpenoid compounds were identified by comparison with a compound database. Results: $T$. carpentariae leaf and T. grandiflora leaf, fruit and nut extracts displayed potent anti-proliferative activity against Caco-2 and HeLa carcinoma cells. The methanolic T. grandiflora leaf extract was particularly effective at blocking the proliferation of the colorectal carcinoma Caco-2 $\left(I C_{50}=372 \mu \mathrm{g} / \mathrm{mL}\right)$. The methanol T. carpentariae and T. grandiflora leaf extracts were similarly potent inhibitors of HeLa cervical cancer cell proliferation with IC50 values of 864 and $833 \mu \mathrm{g} / \mathrm{mL}$ respectively. The methanolic T. grandiflora fruit and nut extracts, as well as all aqueous and ethyl acetate extracts, were moderate to good inhibitors of carcinoma proliferation. In contrast, chloroform and hexane extracts were generally devoid of anti-proliferative activity. The methanolic $T$. grandiflora extracts displayed low toxicity in the Artemia nauplii bioassay. All other extracts were non-toxic. GC-MS analysis of the methanolic T. grandiflora leaf extract identified 3 lanostane and 2 pentacyclic triterpenoids. Conclusion: The low toxicity and anti-proliferative activity observed with the T. carpentariae and T. grandiflora extracts against Caco-2 and HeLa indicate their potential for the prevention and treatment of some cancers.
\end{abstract}

Key words: Combretaceae, Australian plants, Wild peach, Native almond, Anticancer activity, Caco-2, HeLa, chemotherapy.

\section{INTRODUCTION}

The growth and development of healthy cells depends on fine regulation of growth promoting and inhibiting pathways. These pathways are regulated by cellular redox status. Induction of oxidative stress has been linked with numerous diseases including atherosclerosis, diabetes, cirrhosis, ${ }^{1}$ autoimmune disorders and chronic inflammation, ${ }^{2}$ neurodegeneration ${ }^{1}$ and several types of cancer. ${ }^{3,4}$ Chromosome instability (a common feature of many cancers) has also been linked with oxidative stress. ${ }^{4}$ Oxidative stress induced genetic instability may result in the emergence of new tumour phenotypes. Consumption of high levels of antioxidants may block this genetic instability and thus block tumourgenesis, inhibiting cancer formation and/or progression.

Modulation of cellular redox status is also effective for the treatment of established cancers. Many current cancer chemotherapeutic drugs (e.g. doxorubicin, daunorubicin, mitomycin C, etoposide, cisplatin, arsenic trioxide, ionising radiation, photodynamic therapy) are reliant on induction of oxidative stress and the production of ROS for cytotoxicity. Whilst effective against established tumours, these drugs have little effect on inhibiting tumourgenesis. Furthermore, these drugs are associated with a number of unpleasant side effects, including low blood counts, anaemia, increased incidence of infections, tiredness, nausea and vomiting, loss of appetite, constipation or diarrhoea, hair loss and skin reactions/sensitivities. ${ }^{5,6}$ A further worrying trend is the development of resistance to these drugs by some cancers, most commonly by the development of specific transport mechanisms which eject anticancer drugs from the cell, substantially reducing their efficacy. ${ }^{7,8}$ The development of new cancer chemotherapies is a high priority. Drugs which target both tumourgenesis and cancer development would be particularly useful. Similarly, the development of new treatments with pluripotent anticancer mechanisms would be particularly useful due to a lower likelihood for the development of resistance. 
A re-examination of traditional herbal medicines for the discovery of a new generation of anticancer drugs is an attractive prospect as the cytotoxic/cytostatic properties of many medicinal plants have been long recognised and recorded. There has recently been a revival of interest in herbal medications due to a perception that there is a lower incidence of adverse reactions to plant preparations compared to synthetic pharmaceuticals. Furthermore, the use of complex plant derived mixtures or extracts may increase the efficacy of the treatment and may minimise the risk of developing treatment resistant cancers. Indeed, many current frontline cancer drugs (e.g. camptothecin, etoposide, ingenol mebutate, paclitaxol, teniposide, vincristine, and vinblastine) are either derived from plants, or are semi-synthetic analogues of plant compounds.

High antioxidant plant extracts are potential targets for the discovery of novel cancer chemotherapies as they may protect against tumourgenesis, yet also induce cytotoxicity via the induction of oxidative stress and the production of ROS ${ }^{9,10}$ Individual phytochemical components may act as either antioxidants or as oxidants and thus may also be effective in the treatment of cancer, as well as in its prevention at different concentrations. The oxidant/antioxidant effects of plant extracts are due to a balance between the free radical scavenging activities and reducing power of their phytochemical components. ${ }^{10}$ If antioxidant components are present in concentrations and ratios consistent with pro-oxidant activity, the extract would be expected to induce apoptosis and therefore would have anticancer activity. If the levels of components are consistent with a reducing environment, antioxidant activity would result and the extract would not have cytotoxic cancer activity, although it may inhibit tumorigenesis. ${ }^{10,11}$

Plants of the genus Terminalia (family Combretaceae) are characterised by their high antioxidant contents. ${ }^{12}$ Furthermore, several individual Terminalia spp., (and traditional medicine combinations containing Terminalia spp.) have been reported to have potent anticancer properties. The Ayurvedic medicine Triphala (which contains Terminalia belliricia and Terminalia chebula) has cytotoxic effects against thymic lymphoma cells, ${ }^{13,14}$ human breast cancer cell lines, ${ }^{13,15}$ human prostate cancer cell lines and human pancreatic cancer cell lines. ${ }^{16}$ Conversely, the cytotoxic effects of Triphala are negligible in normal cell lines. ${ }^{13,14} T$. belliricia extracts have also demonstrated growth inhibitory effects towards human A549 lung cancer cell lines and HepG2 hepatocarcinoma cell lines without the presence of the other plant components present in Triphala. ${ }^{17} \mathrm{~T}$. belliricia extracts also have synergistic effects with conventional anticancer chemotherapeutics, enhancing the cytotoxic activity of cisplatin and doxorubicin towards the cancer cell lines, indicating their potential as synergistic cancer chemotherapeutic agents.

The Australian species Terminalia ferdinandiana Exell. has received much recent attention due to its extremely high antioxidant content ${ }^{12,18}$ and reports linking antioxidant levels and redox management with anticancer activity. ${ }^{11}$ A recent study reported that a T. ferdinandiana fruit extract rich in polyphenolic compounds displayed anti-proliferative activity against a panel of cancer cell lines. ${ }^{19}$ The proliferation of normal cell lines was also inhibited in that study. The extract activated caspase-7 and caspase-9 as well as poly (ADP-ribose) polymerase (PARP), indicating that apoptosis induction is via an intrinsic pathway. Despite these previous studies, limited information is available on any of the other Australian Terminalia spp. This study screened two Australian Terminalia species (Terminalia carpentariae C.T. White and Terminalia grandiflora Benth.) for the ability to inhibit proliferation of Caco-2 colorectal and HeLa cervical cancer cell lines. The most potent anti-proliferative extract was subsequently analysed by GC-MS and the triterpenoid components were identified.

\section{MATERIALS AND METHODS}

\section{Plant collection}

The Terminalia carpentariae C.T. White leaf and Terminalia grandiflora Benth. leaf, fruit and nut (seed) plant materials used in this study were harvested by the elders of the Groote Esylandt Aboriginal community, Australia and were a kind gift from David Boehme of Northern Territory Wild Harvest. Voucher samples of all plant specimens have been stored at the School of Natural Sciences, Griffith University, Brisbane (Australia). The plant materials were comprehensively desiccated in a Sunbeam food dehydrator and dried materials stored at $-30^{\circ} \mathrm{C}$ for later use. Prior to usage, the materials were thawed and ground into a coarse powder. Individual $1 \mathrm{~g}$ quantities of the materials were weighed into separate tubes and $50 \mathrm{~mL}$ of methanol, deionised water, ethyl acetate, chloroform or hexane were added. All solvents were obtained from Ajax, Australia and were AR grade. The deionised water was sterilised prior to use. The ground plant materials were individually extracted in each solvent for 24 hours at $4^{\circ} \mathrm{C}$ through gentle shaking. The extracts were then filtered through filter paper (Whatman No. 54) under vacuum, followed by drying by rotary evaporation in an Eppendorf concentrator 5301. The resultant extract was weighed and redissolved in $10 \mathrm{~mL}$ deionised water (containing $1 \% \mathrm{DMSO}$ ).

\section{Qualitative phytochemical studies}

Phytochemical analysis of the $T$. carpentariae and $T$. grandiflora extracts for the presence of saponins, phenolic compounds, flavonoids, polysteroids, triterpenoids, cardiac glycosides, anthraquinones, tannins and alkaloids was conducted by previously described assays. ${ }^{20,21}$

\section{Antioxidant capacity}

The antioxidant capacity of each sample was assessed using a modified DPPH free radical scavenging method ${ }^{9,21}$ Ascorbic acid (0-25 $\mu$ g per well) was used as a reference and the absorbance's were measured and recorded at $517 \mathrm{~nm}$. All tests were performed in parallel with controls on each plate and all were performed in triplicate. The antioxidant capacity based on DPPH free radical scavenging ability was determined for each extract and expressed as $\mu \mathrm{g}$ ascorbic acid equivalence per gram of original plant material extracted.

\section{Screen for anti-cancer bioactivity}

\section{Cancer cell lines}

The Caco-2 and HeLa carcinoma cell lines used in this study were obtained from American Type Culture Collection (Rockville, USA). The cells were cultured in Roswell Park Memorial Institute (RPMI) 1640 medium (Life Technologies), supplemented with $20 \mathrm{mM}$ HEPES, $10 \mathrm{mM}$ sodium bicarbonate, $50 \mu \mathrm{g} / \mathrm{ml}$ streptomycin, $50 \mathrm{IU} / \mathrm{mL}$ penicillin, $2 \mathrm{mM}$ glutamine and $10 \%$ foetal calf serum (Life Technologies). The cells were maintained as monolayers in $75 \mathrm{~mL}$ flasks at $37^{\circ} \mathrm{C}, 5 \% \mathrm{CO}_{2}$ in a humidified atmosphere until approximately $80 \%$ confluent.

\section{Evaluation of cancer cell anti-proliferative activity}

Evaluation of the anti-proliferative activity of the T. carpentariae and T. grandiflora extracts was as previously described. ${ }^{9,22}$ Briefly, $1 \mathrm{~mL}$ of tryp$\sin$ (Sigma) was added to the culture flasks and incubated at $37^{\circ} \mathrm{C}, 5 \%$ $\mathrm{CO}_{2}$ for $15 \mathrm{~min}$ to dislodge the cancer cells. The cell suspensions were then transferred to a $10 \mathrm{~mL}$ centrifuge tube and sedimented by centrifugation. The supernatant was discarded and the cells were resuspended in $9 \mathrm{~mL}$ of fresh media. Aliquots of the resuspended cells $(70 \mu \mathrm{L}$, containing approximately 5000 cells) were added to the wells of a 96 well plate. A volume of $30 \mu \mathrm{L}$ of the test extracts or cell media (for the negative 
control) was added to individual wells and the plates were incubated at $37^{\circ} \mathrm{C}, 5 \% \mathrm{CO}_{2}$ for 12 hours in a humidified atmosphere. A volume of 20 $\mu \mathrm{L}$ of Cell Titre 96 Aqueous One solution (Promega) was subsequently added to each well and the plates were incubated for a further 3 hours. Absorbances were recorded at $490 \mathrm{~nm}$ using a Molecular Devices, Spectra Max M3 plate reader. All tests were performed in at least triplicate and triplicate controls were included on each plate. The anti-proliferative activity of each test was calculated as a percentage of the negative control using the following formula:

Proliferation (\% untreated control) $=\left(\mathrm{A}_{\mathrm{ct}} / \mathrm{A}_{\mathrm{cc}}\right) \times 100$

$\mathrm{A}_{\mathrm{ct}}$ is the corrected absorbance for the test extract (calculated by subtracting the absorbance of the test extract in media without cells from the extract cell test combination) and $\mathrm{A}_{c c}$ is the corrected untreated control (calculated by subtracting the absorbance of the untreated control in media without cells from the untreated cell media combination).

\section{Determination of $\mathrm{IC}_{50}$ values against Caco-2 and HeLa carcinoma cells}

For $\mathrm{IC}_{50}$ determinations, the plant extracts were tested by the Cell Titre 96 colourimetric method across a range of concentrations. The assays were performed as outlined above and graphs of proliferation versus concentration were plotted for each extract. Linear regression was used to calculate the $\mathrm{IC}_{50}$ values.

\section{Toxicity screening}

\section{Reference toxin for toxicity screening}

Potassium dichromate $\left(\mathrm{K}_{2} \mathrm{Cr}_{2} \mathrm{O}_{7}\right)$ (AR grade, Chem-Supply, Australia) was prepared as a $1.6 \mathrm{mg} / \mathrm{mL}$ solution in distilled water and was serially diluted in artificial seawater for use in the Artemia franciscana nauplii bioassay.

\section{Artemia franciscana nauplii toxicity screening}

Toxicity was tested using a modified Artemia franciscana nauplii lethality assay. ${ }^{23,24}$ Briefly, $400 \mu \mathrm{L}$ of seawater containing approximately 53 (mean $52.6, \mathrm{n}=125, \mathrm{SD} 12.8)$ A. franciscana nauplii were added to wells of a 48 well plate and immediately used for bioassay. A volume of $400 \mu \mathrm{L}$ of diluted plant extracts or the reference toxin were transferred to the wells and incubated at $25 \pm 1^{\circ} \mathrm{C}$ under artificial light (1000 Lux). A negative control $(400 \mu \mathrm{L}$ seawater) was run in triplicate for each plate. All treatments were performed in at least triplicate. The wells were checked at regular intervals and the number of dead counted. The nauplii were considered dead if no movement of the appendages was observed within 10 seconds. After $72 \mathrm{~h}$, all nauplii were sacrificed and counted to determine the total \% mortality per well. The $\mathrm{LC}_{50}$ with $95 \%$ confidence limits for each treatment was calculated using probit analysis.

\section{Non-targeted GC-MS analysis}

Separation and quantification of phytochemical components were performed using a Shimadzu GC-2010 Plus (USA) linked to a Shimadzu MS TQ8040 (USA) mass spectrometer. The system was equipped with a Shimadzu auto-sampler AOC-5000 Plus (USA). Chromatographic separation was accomplished using a (5\% phenyl, $95 \%$ dimethylpolysiloxane, $30 \mathrm{~m} \times 0.25 \mathrm{~mm}$ id $\times 0.25 \mu \mathrm{m}$ ) capillary column, obtained from (Restek USA). Helium (99.999\%) was employed as a carrier gas at a flow rate of $0.75 \mathrm{~mL} / \mathrm{min}$ at a split ratio of $21: 1$. The injector temperature was set at $280^{\circ} \mathrm{C}$. The initial column temperature was held at $40{ }^{\circ} \mathrm{C}$ for $5 \mathrm{~min}$, with an initial ramp at $5^{\circ} \mathrm{C}$ per min to acquire a temperature of $140^{\circ} \mathrm{C}$ which was subsequently maintained for a minute. A second ramp was initiated at $20^{\circ} \mathrm{C}$ per min, to attain a column temperature of $260^{\circ} \mathrm{C}$, and held for a minute. The third ramp of $50^{\circ} \mathrm{C}$ per min was commenced to reach a final temperature of $300{ }^{\circ} \mathrm{C}$, which was maintained for a duration of $5 \mathrm{~min}$. The mass spectrometer was operated in the electron ionisation mode at $70 \mathrm{eV}$. The analytes were then recorded in total ion count (TIC) mode. The TIC was acquired after a min and for a duration of 38.8 mins utilising a mass range of $26-500 \mathrm{~m} / \mathrm{z}$.

\section{Statistical analysis}

Data is expressed as the mean \pm SEM of at least three independent experiments. One way ANOVA was used to calculate statistical significance between control and treated groups with a $P$ value $<0.01$ considered to be statistically significant.

\section{RESULTS}

\section{Extraction yields, qualitative phytochemical evaluation and antioxidant capacity}

Extraction of $1 \mathrm{~g}$ of the various dried Terminalia spp. materials with the solvents yielded dried plant extracts ranging from $16 \mathrm{mg}$ (T. grandiflora nut ethyl acetate extract) to $348 \mathrm{mg}$ (T. carpentariae leaf methanolic extract) (Table 1 ). The leaf extracts generally gave relatively high yields of dried extracted material compared to the fruit and nut extracts. The dried extracts were resuspended in $10 \mathrm{~mL}$ of deionised water (containing $1 \%$ DMSO) resulting in the extract concentrations shown in Table 1.

Qualitative phytochemical studies showed that methanol and water extracted the greatest amount and widest range of phytochemicals (Table 1). These solvents extracted high levels of water soluble phenolics, moderate to high levels of tannins, as well as low levels of flavonoids and anthraquinones for all Terminalia samples tested. Saponins were also generally present in the methanolic and aqueous extracts, although the levels of this class of compound were more variable. The ethyl acetate extracts generally extracted similar but lower phytochemical profiles as compared to the methanolic and aqueous extracts. In contrast, the chloroform and hexane extracts were devoid of detectable levels of all classes of phytochemicals.

Antioxidant capacity for the plant extracts (Table 1) ranged from below the threshold of detection to a high of $1260 \mu \mathrm{g}$ (methanolic T. grandiflora leaf extract) ascorbic acid equivalence per gram of dried plant material extracted. The methanolic and aqueous extracts typically had higher antioxidant capacities than the corresponding ethyl acetate, chloroform and hexane extracts. Indeed, the antioxidant capacity of all ethyl acetate, chloroform and hexane extracts was below the threshold of detection. A further trend was apparent: the leaf extracts had higher antioxidant capacities than those determined for the corresponding fruit or nut extracts.

\section{Anti-proliferative activity}

Aliquots of each extract were tested for the ability to block cell proliferation of Caco-2 (Figure 1) and HeLa (Figure 2) cell lines. The aqueous, chloroform and hexane T. carpentariae leaf extracts displayed significant $(\mathrm{p}<0.01)$ anti-proliferative effects against Caco- 2 cells (Figure 1a). The chloroform extract was particularly potent, inhibiting cell proliferation to approximately $39 \%$ of the untreated control Caco- 2 cell proliferation. The aqueous and hexane extracts were also good inhibitors of Caco-2 proliferation, albeit with higher levels of proliferation determined (approximately 71 and 59\% of the untreated control Caco2 cell proliferation respectively). Inhibition of proliferation by the $T$. carpentariae leaf extracts was dose dependent, with the level of inhibitory activity decreasing at lower concentrations (Table 2).

The T. grandiflora leaf extracts (Figure $1 \mathrm{~b}$ ) were substantially more effective anti-proliferative agents than were the T. carpentariae leaf extracts. Indeed, a decrease in cellular metabolic activity below the start- 
Table 1: The mass of dried extracted plant material, the concentration after resuspension in deionised water (1\% DMSO) and qualitative phytochemical screenings of the $T$. carpentariae and $T$. grandiflora extracts.

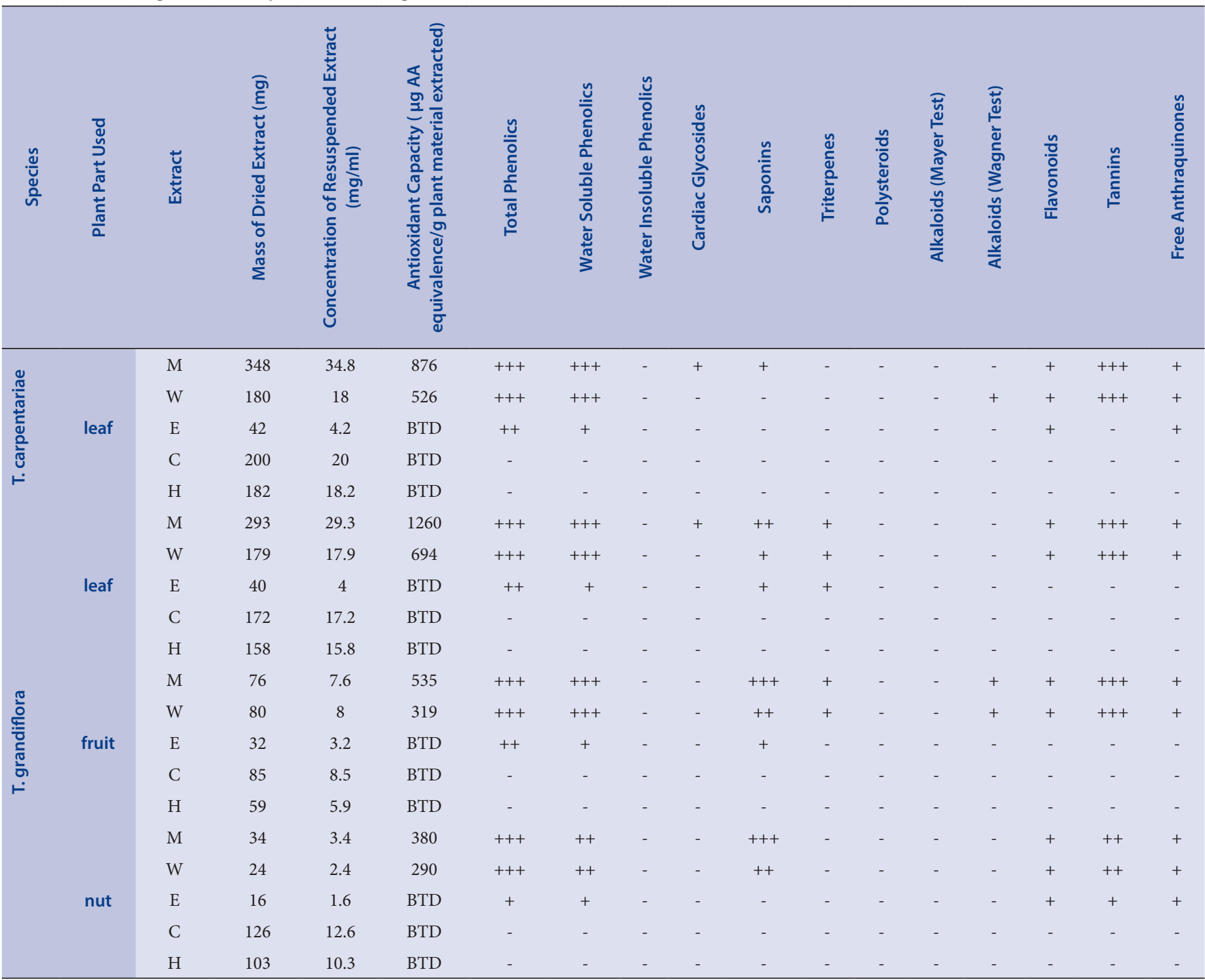

+++ indicates a large response; ++ indicates a moderate response; + indicates a minor response; - indicates no response in the assay. $\mathrm{AA}=$ ascorbic acid; $\mathrm{M}=\mathrm{metha}-$ nolic extract; $\mathrm{W}=$ aqueous extract; $\mathrm{E}=$ ethyl acetate extract; $\mathrm{C}=$ chloroform extract; $\mathrm{H}=$ hexane extract; $\mathrm{BTD}=$ below the threshold of detection.

ing level was evident for the Caco-2 cells exposed to the methanolic T. grandiflora leaf extract ( $-22 \%$ proliferation). This may indicate that apoptotic mechanisms were responsible for the inhibition of proliferation induced by this extract. The aqueous, ethyl acetate, chloroform and hexane extracts were also good anti-proliferative agents, with approximately $36,61,44$ and $52 \%$ proliferation determined respectively (compared to the untreated control cells). The T. grandiflora fruit (Figure 1c) and nut (Figure 1d) extracts were also good inhibitors of Caco-2 carcinoma cell proliferation, albeit, generally inducing a lower inhibition of cell proliferation than determined for the T. grandiflora leaf extracts.

The T. carpentariae and T. grandiflora extracts were similarly effective at inhibiting HeLa cancer cell proliferation (Figure 2). Indeed, with some notable exceptions, the extracts were generally more potent HeLa growth inhibitors than Caco- 2 inhibitors (as judged by \% inhibition of proliferation). As reported for Caco- 2 cell proliferation, the polar to mid polarity methanolic, aqueous, ethyl acetate and chloroform extracts were the most effective inhibitors of HeLa proliferation. The methanolic T. carpentariae leaf extract essentially blocked cell proliferation completely (98 \% inhibition). The aqueous, ethyl acetate and chloroform extracts were also effective at inhibiting HeLa proliferation, with rates of approximately 12, 44 and $40 \%$ of the untreated control HeLa cell proliferation respectively. The hexane T. carpentariae leaf extract was devoid of HeLa proliferation inhibitory activity. As for inhibition of Caco-2 proliferation, the effect was dose dependent, with the level of inhibitory activity decreasing at lower concentrations (Table 2).

The T. grandiflora leaf extracts (Figure $2 \mathrm{~b}$ ) were more potent inhibitors of HeLa cell proliferation than were the T. carpentariae leaf extracts. Indeed, a decrease in cellular metabolic activity below the starting level was evident for the HeLa cells exposed to the methanolic T. grandiflora leaf extract ( $-4 \%$ proliferation). The aqueous, ethyl acetate, and chloroform extracts were also good anti-proliferative agents, with approximately 12,44 and $40 \%$ proliferation respectively (compared to the untreated control cells). The T. grandiflora fruit (Figure 2c) and nut (Figure 2d) extracts were also good inhibitors of HeLa carcinoma cell proliferation, 


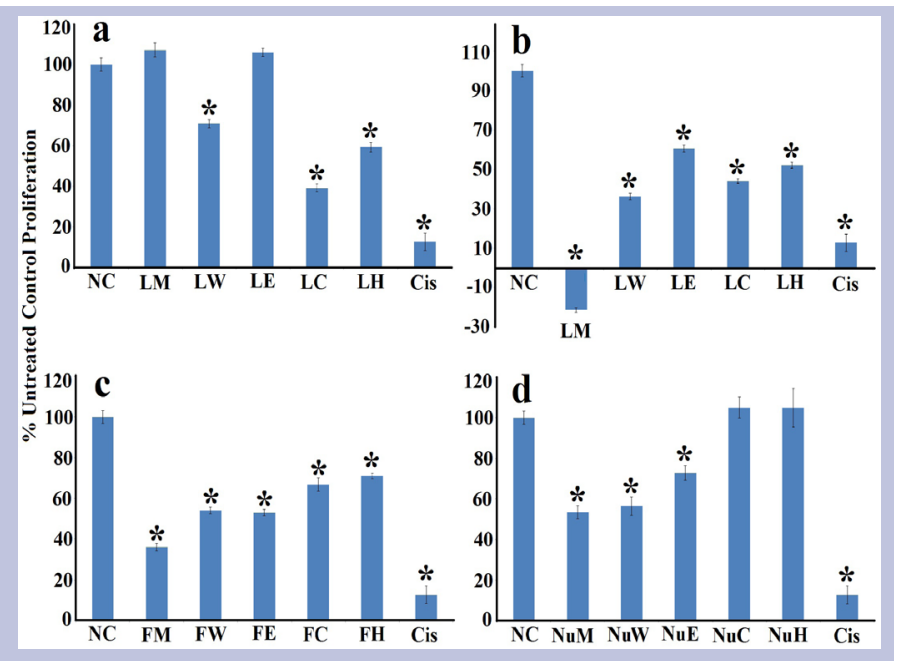

Figure 1: Anti-proliferative activity of (a) T. carpentariae leaf extracts, (b) T. grandiflora leaf extracts, (c) T. grandiflora fruit extracts and (d) T. grandiflora nut extracts against Caco- 2 carcinoma cells measured as percentages of the untreated control cells. Results are expressed as mean percentages \pm SEM of triplicate determinations. $\mathrm{L}=$ leaf; $\mathrm{F}=$ fruit; $\mathrm{Nu}=$ nut; $\mathrm{M}=$ methanolic extract; $\mathrm{W}=$ aqueous extract; $\mathrm{E}=$ ethyl acetate extract; $\mathrm{C}=$ chloroform extract; $\mathrm{H}=$ hexane extract; $\mathrm{NC}=$ negative (untreated) control; $\mathrm{Cis}=$ cisplatin control (50 $\mu \mathrm{g} / \mathrm{mL}) .{ }^{*}$ indicates results that are significantly different to the negative control $(\mathrm{P}<0.01)$.

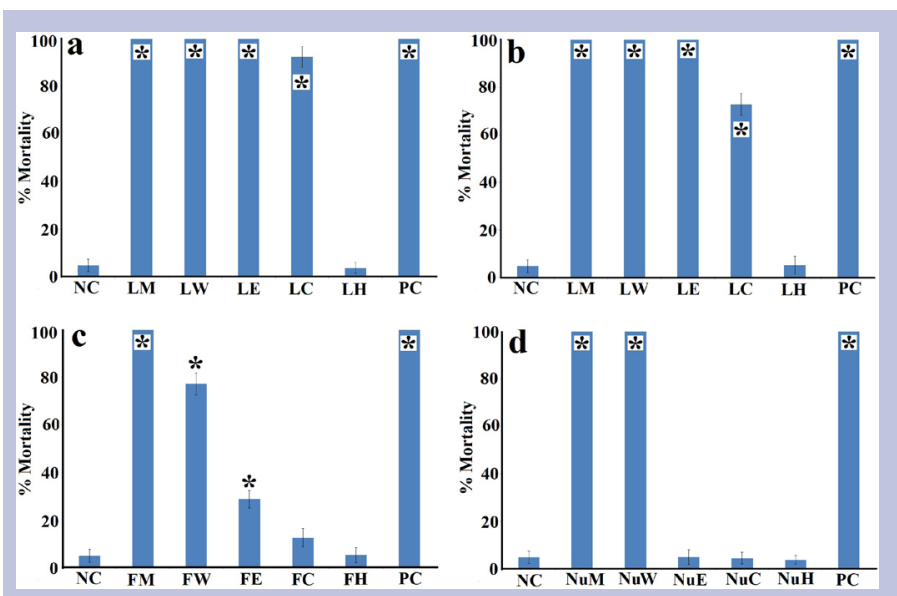

Figure 3: The lethality of (a) T. carpentariae leaf extracts, (b) T. grandiflora leaf extracts, (c) T. grandiflora fruit extracts and (d) T. grandiflora nut extracts towards Artemia franciscana nauplii after 24 hours exposure. Results are expressed as mean percentages \pm SEM of triplicate determinations. $L=$ leaf; $F=$ fruit; $\mathrm{Nu}=$ nut; $\mathrm{M}=$ methanolic extract; $\mathrm{W}=$ aqueous extract; $\mathrm{E}=$ ethyl acetate extract; $\mathrm{C}=$ chloroform extract; $\mathrm{H}$ = hexane extract; $\mathrm{NC}=$ negative (seawater) control; $\mathrm{PC}=$ potassium dichromate control $(1000 \mu \mathrm{g} / \mathrm{mL}) .{ }^{*}$ indicates results that are significantly different to the negative control $(P<0.01)$.

albeit, generally inducing a lower inhibition of cell proliferation than determined for the T. grandiflora leaf extracts. For all T. grandiflora plant parts, the methanolic extract was a particularly potent inhibitor of proliferation, each inhibiting HeLa proliferation by $>90 \%$ (compared to the untreated control cells).

The anti-proliferative efficacy of the extracts against HeLa and Caco-2 cells was further quantified by determining the dose required to inhibit to $50 \%\left(\mathrm{IC}_{50}\right)$ of the control cell proliferation (Table 2). Several of the extracts were effective at inhibiting cancer cell proliferation at low to moderate concentrations, with $\mathrm{IC}_{50}$ values against both cell lines

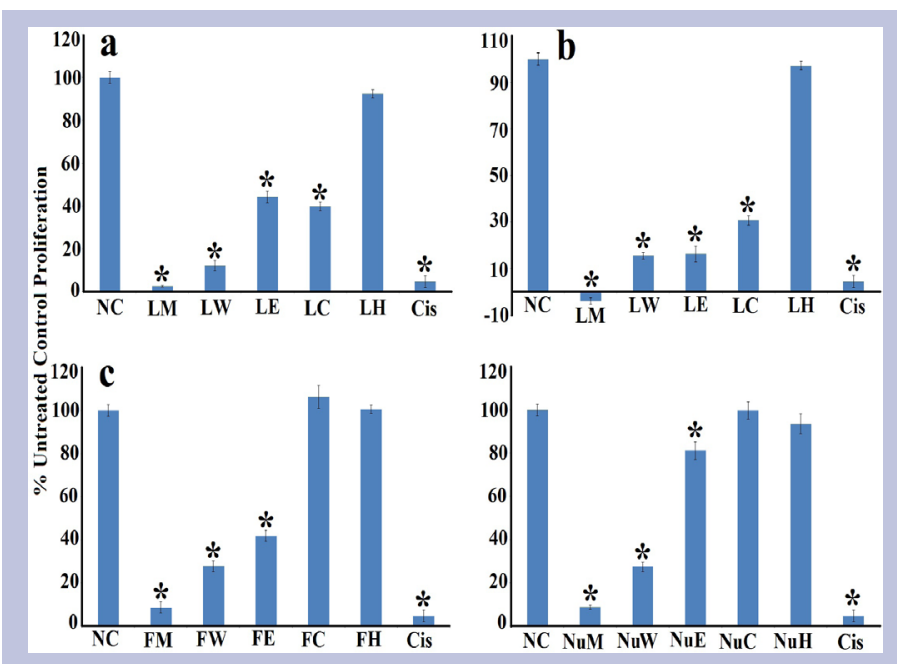

Figure 2: Anti-proliferative activity of (a) T. carpentariae leaf extracts, (b) $T$. grandiflora leaf extracts, (c) T. grandiflora fruit extracts and (d) T. grandiflora nut extracts against HeLa carcinoma cells measured as percentages of the untreated control cells. Results are expressed as mean percentages \pm SEM of triplicate determinations. $\mathrm{L}=$ leaf; $\mathrm{F}=$ fruit; $\mathrm{Nu}=$ nut; $\mathrm{M}=$ methanolic extract; $\mathrm{W}=$ aqueous extract; $\mathrm{E}=$ ethyl acetate extract; $\mathrm{C}=$ chloroform extract; $\mathrm{H}=$ hexane extract; $\mathrm{NC}=$ negative (untreated) control; $\mathrm{Cis}=$ cisplatin control (50 $\mu \mathrm{g} / \mathrm{mL}$ ). ${ }^{*}$ indicates results that are significantly different to the negative control $(P<0.01)$.

substantially $<1000 \mu \mathrm{g} / \mathrm{mL}$. The methanolic $T$. grandiflora leaf extract was particularly effective with $\mathrm{IC}_{50}$ values of 372 and $833 \mu \mathrm{g} / \mathrm{mL}$ against the Caco-2 and HeLa cell lines respectively. Potent anti-proliferative activity was also determined for the methanolic extracts of all other Terminalia spp. plant parts. Indeed, the T. carpentariae leaf $\left(\mathrm{HeLa} \mathrm{IC} \mathrm{IC}_{50}=864 \mu \mathrm{g} /\right.$ $\mathrm{mL}), T$. grandiflora fruit (Caco-2 $\mathrm{IC}_{50}=720 \mu \mathrm{g} / \mathrm{mL} ; \mathrm{HeLa} \mathrm{IC}_{50}=736 \mu \mathrm{g} /$ $\mathrm{mL}$ ) and T. grandiflora nut (Caco-2 $\mathrm{IC}_{50}=457 \mu \mathrm{g} / \mathrm{mL}$; HeLa $\mathrm{IC}_{50}=740$ $\mu \mathrm{g} / \mathrm{mL}$ ) methanolic extracts all had $\mathrm{IC}_{50}$ values indicative of potent antiproliferative activity. The aqueous carpentariae leaf extract $\left(\mathrm{HeLa} \mathrm{IC} \mathrm{IC}_{50}=\right.$ $983 \mu \mathrm{g} / \mathrm{mL}$ ), ethyl acetate T. grandiflora leaf and fruit extracts ( $\mathrm{HeLa} \mathrm{IC}_{50}$ $=869$ and $592 \mu \mathrm{g} / \mathrm{mL}$ respectively) and the aqueous T. grandiflora nut extract $\left(\mathrm{HeLa} \mathrm{IC} \mathrm{I}_{50}=670 \mu \mathrm{g} / \mathrm{mL}\right)$ were similarly potent anti-proliferative agents, with $\mathrm{IC}_{50}$ values substantially $<1000 \mu \mathrm{g} / \mathrm{mL}$. Several other extracts also displayed good anti-proliferative activity, albeit with $\mathrm{IC}_{50}$ values $>1000 \mu \mathrm{g} / \mathrm{mL}$, indicating moderate anti-proliferative activity.

\section{Quantification of toxicity}

The plant extracts were serially diluted in artificial seawater for toxicity testing in the Artemia nauplii lethality bioassay. For comparison, the reference toxin potassium dichromate was also tested. Figure 3 shows the $\%$ mortality induced in the Artemia nauplii following 24 hours of exposure. Potassium dichromate (reference toxin) was rapid in its induction of mortality, inducing the onset of mortality within the first 4 hours of exposure (results not shown). By 24 hours of exposure, potassium dichromate had induced $100 \%$ mortality in the Artemia nauplii. Similarly, several extracts also induced mortality significantly above that of the seawater control. With the exception of the hexane extracts, all T. carpentariae leaf extracts (Figure 3a) and T. grandiflora leaf extracts (Figure $3 \mathrm{~b}$ ) displayed apparent toxicity, inducing substantially $>50 \%$ mortality following $24 \mathrm{~h}$ exposure. Several of the T. grandiflora fruit/nut extracts also induced significant mortality. The methanolic and aqueous extracts of both the fruit and nut induced $\geq 50 \%$ mortality following $24 \mathrm{~h}$ exposure. Whilst the T. grandiflora fruit ethyl acetate extract also induced mortality significantly higher than the seawater control, the mortality was $<50 \%$. Therefore this extract was deemed to be nontoxic. 
All other extracts displayed mortality levels similar to those determined for the seawater control and thus were also deemed to be nontoxic.

To further quantify the toxicity of the extracts that were shown to induce significant mortality for comparison with other toxins, the $\mathrm{LC}_{50}$ values of the extracts was determined by testing across the concentration range $2000 \mu \mathrm{g} / \mathrm{ml}$ to $125 \mu \mathrm{g} / \mathrm{mL}$ in the Artemia nauplii bioassay. For comparison, potassium dichromate was tested across the same concentration range. Table 2 shows the $\mathrm{LC}_{50}$ values of the extracts which had shown toxicity towards A. franciscana. Whilst the T. carpentariae and T. grandiflora leaf methanolic, aqueous, ethyl acetate and chloroform extracts, as well as the T. grandiflora fruit and nut methanolic and aqueous extracts, initially appeared toxic in the extract mortality screening study (Figure 3 ), determination of their $\mathrm{LC}_{50}$ values demonstrated that most were nontoxic as $\mathrm{LC}_{50}$ values of $\geq 1000 \mu \mathrm{g} / \mathrm{mL}$ in the Artemia nauplii bioassay have previously been defined as non-toxic [24]. $\mathrm{LC}_{50}$ values $<1000 \mu \mathrm{g} / \mathrm{mL}$ were only determined for the methanolic T. grandiflora extracts (leaf, fruit and nut). These extracts were therefore deemed to be toxic. It is noteworthy that the bioassay organism (Artemia franciscana) is sensitive to extreme $\mathrm{pH}$ ranges. Interestingly, the T. grandiflora methanolic extracts which have $\mathrm{LC}_{50}$ values $<1000 \mu \mathrm{g} / \mathrm{mL}$ have higher relative antioxidant capacities than the other solvent extractions for each plant specimen (Table 1). Furthermore, the high antioxidant capacities of other Terminalia spp. extracts are largely due to their high ascorbic acid contents. ${ }^{12}$ Therefore, the apparent toxicity determined for the methanolic T. grandiflora leaf, fruit and nut extracts may be fallacious and instead be a result of the extracts' high ascorbic acid contents.

\section{Qualitative GC-MS analysis of the methanolic T. grandiflora leaf extract}

The methanolic T. grandiflora leaf extract displayed the most potent antiproliferative activity against both Caco- 2 and HeLa carcinoma cell lines and was therefore deemed the most promising extract for further GCMS analysis (Figure 4). As many triterpenoids have well established antiproliferative effects against a wide variety of tumour cells, ${ }^{25,26}$ our study focussed on detecting and identifying the triterpenoid components. The resultant gas chromatogram (Figure 4a) and mass spectral data (Figures 4b-f) was examined for the presence of triterpenoids by comparison with a GC-MS mass and spectral database. In total, 85 unique mass signals were noted for the methanolic T. grandiflora leaf extract by GC-MS analysis (results not shown). Empirical formulas were determined for all of these compounds. Comparison of the mass spectra and chromatographic retention of these mass signals against a GC-MS mass and spectral database putatively detected 5 compounds with mass spectra consistent with triterpenoids (Figures $4 \mathrm{~b}-\mathrm{f}$ ):

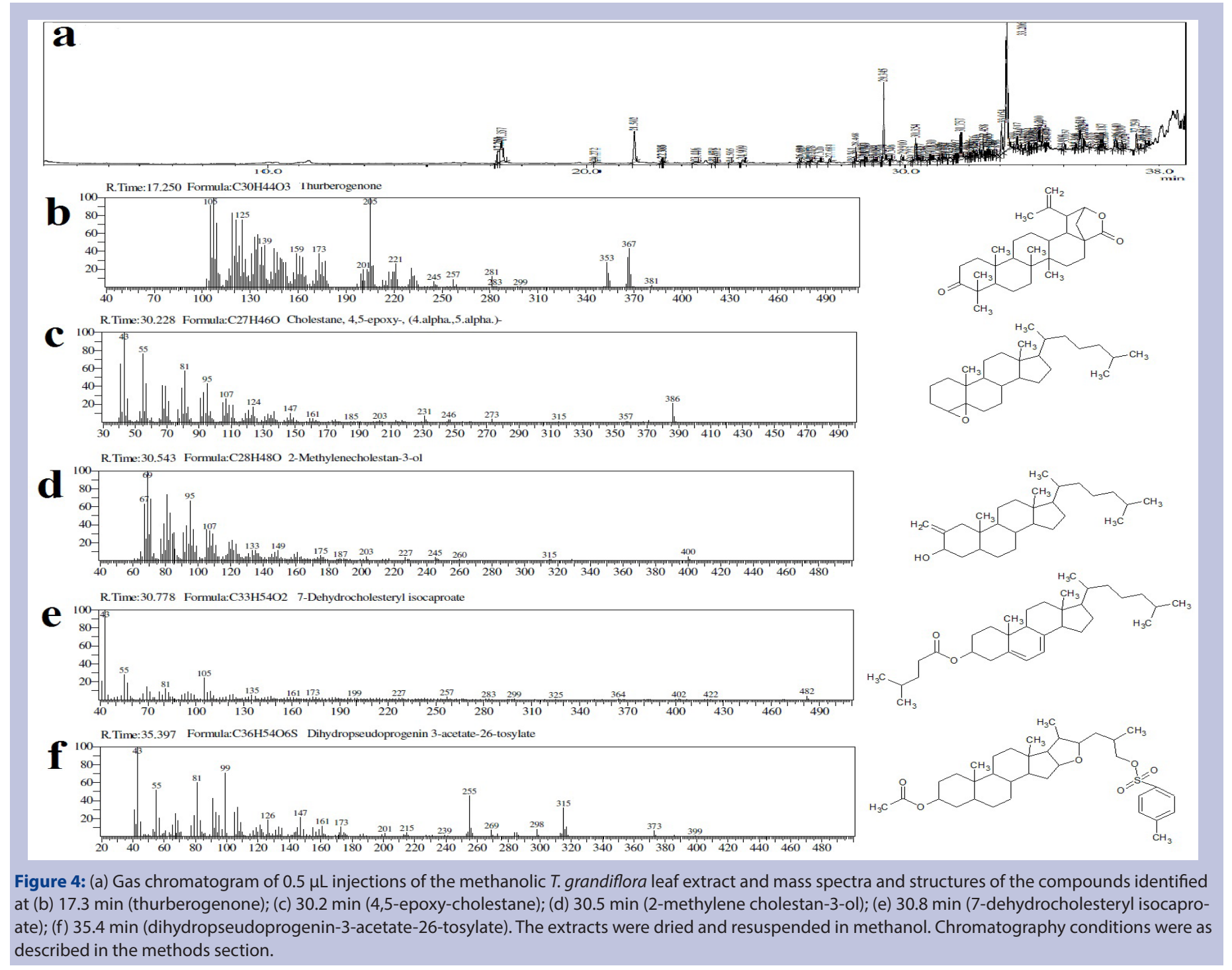




\section{Thurbergenone}

(Figure 4b): (synonyms Lup-20(30)-en-28-oic acid, $19 \beta$-hydroxy-3oxo-, $\gamma$-lactone; 21,28-Epoxylup-20(29)-ene-3, 28-dione); Molecular formula $\mathrm{C}_{30} \mathrm{H}_{44} \mathrm{O}_{3}$; Retention time (17.25 min); $\mathrm{MW}$ (calculated) = 452.669; MW (measured) = m/z (M) 453; (M-72) 381; (M-86) 367; (M154) 299; (M-172) 281; (M-196) 257; (M-208) 245; (M-222) 231; (M232) 221; (M-248) 205; (M-280) 173; (M-294) 159; (M-314) 139; (M328) 125; (M-348) 105.

\section{4,5-Epoxy- (4a, 5a) cholestane}

(Figure 4c): Molecular formula $\mathrm{C}_{27} \mathrm{H}_{46} \mathrm{O}$; Retention time (30.23 min); MW $($ calculated $)=386.654 ; \mathrm{MW}($ measured $)=\mathrm{m} / \mathrm{z}(\mathrm{M}) 386 ;(\mathrm{M}-29)$ 357; (M-71) 315; (M-113) 273; (M-140) 246; (M-155) 231; (M-183) 203; (M-201) 185; (M-225) 161; (M-239) 147; (M-262) 124; (M-279) 107; (M291) 95; (M-305) 81; (M-331) 55; (M-343) 43.

\section{2-Methylenecholestan-3-ol}

(Figure 4d): Molecular formula $\mathrm{C}_{28} \mathrm{H}_{48} \mathrm{O}$; Retention time (30.54 min); $\mathrm{MW}($ calculated $)=400.68 ; \mathrm{MW}($ measured $)=\mathrm{m} / \mathrm{z}(\mathrm{M}) 400 ;(\mathrm{M}-85) 315$; (M-140) 260; (M-155) 245; (M-173) 227; (M-197) 203; (M-213) 187; (M225) 175; (M-251) 149; (M-267) 133; (M-293) 107; (M-305) 95; (M-319) 81; (M-331) 69.

\section{7-Dehydrocholesteryl isocaproate}

(Figure 4e): (synonyms cholesta-5,7-dien-3-yl, 4-methylpentoate; pentoic acid, 4-methyl-cholesta-5,7-dien-3-yl ester); Molecular formula $\mathrm{C}_{33} \mathrm{H}_{54} \mathrm{O}_{2}$; Retention time (30.78 min); $\mathrm{MW}$ (calculated) $=482.781$; $\mathrm{MW}$ (measured) $=\mathrm{m} / \mathrm{z}(\mathrm{M})$ 482; (M-60) 422; (M-118) 364; (M-157) 325; (M183) 299; (M-199) 283; (M-225) 257; (M-255) 227; (M-283) 199; (M309) 173; (M-321) 161; (M-347) 135; (M-377) 105; (M-401) 81; (M-427) 55; (M-439) 43.

\section{Dihydropseudoprogenin-3-acetate-26-tosylate}

(Figure 4f): (synonym 26(((4-Methylphenyl)sulfonyl) oxy) furostan-3-yl acetate); Molecular formula $\mathrm{C}_{36} \mathrm{H}_{54} \mathrm{O}_{6} \mathrm{~S}$; Retention time (35.40 min); MW (calculated) $=614.875 ; \mathrm{m} / \mathrm{z}(\mathrm{M}-216) 399 ;(\mathrm{M}-242) 373 ;(\mathrm{M}-300) 315$; (M-317) 298; (M-346) 269; (M-260) 255; (M-376) 239; (M-400) 215; (M414) 201; (M-442) 173; (M-454) 161; (M-468) 147; (M-489) 126; (M516) 99; (M-534) 81; (M-560) 55; (M-572) 43.

\section{DISCUSSION}

The effective maintenance of cellular redox state is required for the normal functioning of all living systems. This redox maintenance involves a regulated balance between oxidants and antioxidants, using a variety of antioxidant mechanisms. ${ }^{11}$ These cellular redox

\begin{tabular}{|c|c|c|c|c|}
\hline & \multirow[t]{2}{*}{ Extract } & \multicolumn{2}{|c|}{ Antiproliferative Activity $\mathrm{IC}_{50}(\mu \mathrm{g} / \mathrm{mL})$} & \multirow{2}{*}{ Artemia nauplii $\mathrm{LC}_{50}(\mu \mathrm{g} / \mathrm{mL})$} \\
\hline & & Caco-2 & HeLa & \\
\hline \multirow{4}{*}{ 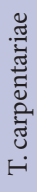 } & L M & - & 864 & 1160 \\
\hline & L W & CND & 983 & 1336 \\
\hline & LE & - & 1071 & 1553 \\
\hline & L C & 1286 & 3783 & 3280 \\
\hline \multirow{17}{*}{ 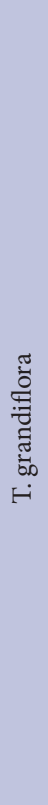 } & L H & CND & - & - \\
\hline & L M & 372 & 833 & 734 \\
\hline & L W & 3222 & 2644 & 1136 \\
\hline & L E & CND & 869 & 1780 \\
\hline & L C & 3729 & 3909 & 3468 \\
\hline & $\mathrm{LH}$ & CND & - & - \\
\hline & F M & 1504 & 720 & 736 \\
\hline & F W & CND & 1873 & 2876 \\
\hline & F E & CND & 592 & - \\
\hline & F C & CND & CND & - \\
\hline & F H & CND & CND & - \\
\hline & $\mathrm{Nu} \mathrm{M}$ & CND & 457 & 740 \\
\hline & $\mathrm{Nu} \mathrm{W}$ & CND & 670 & 1488 \\
\hline & $\mathrm{Nu} E$ & CND & CND & - \\
\hline & $\mathrm{Nu} C$ & - & - & - \\
\hline & $\mathrm{Nu} \mathrm{H}$ & - & - & - \\
\hline & $\mathrm{P}$ & 6.9 & 8.5 & 154 \\
\hline
\end{tabular}

Numbers indicate the mean IC50 or LC50 values of triplicate determinations. - indicates no significant anti-proliferative activity, or that the brine shrimp mortality did not exceed $50 \%$ at any dose tested. CND indicates that whilst significant inhibition of proliferation was observed, an IC50 could not be determined as the inhibition did not exceed $50 \%$ at any concentration tested. $\mathrm{L}=$ leaf; $\mathrm{F}=$ fruit; $\mathrm{Nu}=$ nut; $\mathrm{M}=$ methanolic extract; $\mathrm{W}=$ aqueous extract; $\mathrm{E}=$ ethyl acetate extract; $\mathrm{C}=$ chloroform extract; $\mathrm{H}=$ hexane extract; $\mathrm{P}=$ positive control (cisplatin for anti-proliferative assays; potassium dichromate for toxicity assays). 
defence mechanisms include enzymatic antioxidants (superoxide dismutase, catalase, thioredoxin, thioredoxin reductase, glutathione peroxidase and glutathione peroxidase) and nonenzymatic antioxidants (glutathione, vitamins A, C and E). Deregulation of the redox balance has been implicated in numerous diseases, including atherosclerosis, diabetes, cirrhosis, ${ }^{1}$ autoimmune disease and chronic inflammation, ${ }^{2}$ neurodegeneration ${ }^{1}$ and cancer, (particularly in tumour initiation and tumour promotion). ${ }^{3,4}$ Epidemiological studies have shown that a diet rich in antioxidants is associated with a decreased incidence of chronic diseases. ${ }^{27}$ Individuals with elevated dietary intakes of non-enzymatic antioxidants such as vitamins $\mathrm{A}, \mathrm{C}$ and $\mathrm{E}$ are less likely to suffer many chronic illnesses and some forms of cancer. ${ }^{27,28}$

Antioxidants contribute to reducing oxidative damage via nonenzymatic mechanisms and the scavenging of free radicals. However, studies into the medicinal effects of antioxidants have proved confusing, with some studies showing therapeutic effects ${ }^{29,30}$ whilst other studies indicate that these antioxidants may themselves be toxic. ${ }^{31,32}$ The effects of antioxidants are dose dependent, with low doses behaving as antioxidants, while high doses induce toxicity through the induction of oxidative stress. ${ }^{33}$ Multicellular organisms require a reducing environment for cell proliferation. This is accomplished when there are high levels of reduced glutathione (GSH) levels and low levels of the antioxidant proteins superoxide dismutase (SOD), glutathione peroxidise (GPx) and catalase. ${ }^{34,35}$ Low levels of antioxidants induce cell proliferation whilst high levels inhibit it. ${ }^{36}$ Thus, proliferation favours a reducing environment. ${ }^{37,38}$ Consumption of phenolic antioxidants may help to reduce the oxidative stress of the cell and the whole organism, and thus inhibit cellular proliferation.

The anti-proliferative efficacy of T. carpentariae and T. grandiflora was examined against two cancer cell lines in vitro in this study; $\mathrm{HeLa}$ (cervical) and CaCo-2 (colorectal). Several Australian Terminalia spp. have been previously shown to have high antioxidant contents using Trolox equivalence antioxidant content (TEAC) and photochemiluminescence (PCL) assays. ${ }^{9} 12,18$ Our study confirmed the relatively high antioxidant contents of the T. carpentariae and T. grandiflora extracts using a DPPH free radical scavenging assay. Interestingly, the antioxidant capacity was related to the anti-proliferative activity towards Caco- 2 and HeLa cancer cells. The methanolic extracts displayed the most potent anti-proliferative activity against both cancer cell lines. These extracts consistently had the highest antioxidant capacity of all of the solvent extractions. Indeed, the antioxidant capacity of the T. carpentariae and T. grandiflora methanolic leaf extracts was approximately double the antioxidant capacity of the other corresponding solvent extractions. The methanolic extracts also had substantially more potent anti-proliferative activity than determined for the other solvent extractions. Conversely, extracts for which the antioxidant capacity was below the threshold of detection (ethyl acetate, chloroform and hexane extractions) were inactive or displayed only moderate anti-proliferative activity.

A previous study on the antioxidant activity of fresh apples reported a similar relationship between antioxidant activity and anti-proliferative activity against Caco- 2 cells. ${ }^{39}$ The authors of that study suggested that the anti-proliferative activity was due to the combination of phenolic acids, flavonoids and terpenoids. This correlates with the results observed in the qualitative phytochemical analysis of this report. Phenolic compounds were observed to be present in high levels in all of the extracts that displayed anti-proliferative activity, and in much lower levels in the extracts that did not block cell proliferation. Phenolic compounds protect cells from disease by shielding lipids, proteins and DNA from oxidative damage. ${ }^{40}$ Previous in vitro bioactivity studies of phenolic compounds have demonstrated anti-inflammatory, antioxidant, and anticancer activity. ${ }^{40}$
As the methanolic T. grandiflora leaf extract displayed the most potent anti-proliferative activity against both Caco-2 $\left(\mathrm{IC}_{50}=372 \mu \mathrm{g} / \mathrm{mL}\right)$ and HeLa cells $\left(\mathrm{IC}_{50}=833 \mu \mathrm{g} / \mathrm{mL}\right.$ ), it was deemed the most promising for phytochemical evaluation. Our study focussed on identification of the triterpenoid components as triterpenoids have been reported to have potent anticancer activity. ${ }^{26}$ Five triterpenoids were detected in the methanolic T. grandiflora leaf extract. One of these was identified as the pentacyclic triterpenoid thurberogenone. Whilst we were unable to find reports of anticancer properties for this compound, many other pentacyclic triterpenoids have anticancer activities. Multiple ursane triterpenoids are cytotoxic to NTUB1 bladder cancer cells. ${ }^{41}$ That study reported that the ursane triterpenoids inhibited the cell cycle by downregulated the levels of cyclins (D1 and E) and cyclin-dependent kinases (CDK2 and CDK4), effectively blocking cell cycle progression. Furthermore, the ursane triterpenoids induced apoptosis via p53 mediated p38 MAPK activation pathways. Thus, ursane triterpenoids may be particularly useful as anticancer chemotherapeutics as they block proliferation and stimulate apoptosis. Other studies have reported similar effects for ursane triterpenoids against other carcinoma cell lines. Ursolic acid is a potent inhibitor of MCF-7 mammary cancer cells via the inhibition of cell cycle progression through the G1 phase of the cell cycle. ${ }^{42}$ Further studies have also demonstrated cytotoxicity towards MCF-7 cells. ${ }^{43}$ Ursolic acid suppresses multiple kinases and activator proteins (including p38 MAPK) in 184B4/HER mammary carcinoma cells. ${ }^{44}$ Similarly, oleanane triterpenoids (another class of pentacyclic triterpenoids) inhibit MCF-7/HER cell proliferation by decreasing HER2 phosphorylation and inhibiting cyclin D1 expression, as well as inducing apoptosis. ${ }^{45}$

Three of the other triterpenoids detected in the methanolic T. grandiflora leaf extract were quadracyclic lanostane type triterpenoids. Several similar lanostane triterpenoids have anticancer activities. The lanostane triterpenoid inotodiol isolated from Inonotus obliquus inhibits mouse P388 leukemia cells. ${ }^{46}$ The authors reported that inotodiol induces DNA fragmentation and caspase 3/7 activation. Ganoderic acid triterpenoids suppress MDA-MB-231 breast cancer growth and invasive behaviour by inhibiting AP-1 and NF- $\mathrm{BB}$ transcription factors, resulting in a down regulation of $\mathrm{Cdk} 4$ expression and an inhibition of uPA secretion. ${ }^{47}$ Another lanostane triterpenoid (dehydroebriconic acid) isolated from the traditional Chinese medicine (TCM) plant Poria cocos is a potent inhibitor of DNA topoisomerase $\mathrm{II}^{48}$ and thus would inhibit cell proliferation. Whilst we were unable to find reports of anticancer properties for the triterpenoids identified in our study, it is possible that they may inhibit cell proliferation by similar mechanisms.

A recent study reported that T. carpentariae and T. grandiflora extracts prepared in the same way as in our study contained a diversity of monoterpenoid and sesquiterpenoid components. ${ }^{49}$ a-Citronellol, a-terpineol and caryophyllene were reported to be particularly prevalent in that study. Interestingly, several mono- and sesquiterpenoids have also been reported to suppress NF- $\kappa \mathrm{B}$ signalling pathways. NF- $\kappa \mathrm{B}$ is produced in response to free radicals and cell stress and its incorrect regulation may result in tumourgenesis. ${ }^{47}$ It controls DNA transcription and downregulation of NF- $\kappa B$ results in increased susceptibility to apoptosis. Thus, the monoterpenoid and sesquiterpenoid components may function by both inhibiting proliferation by blocking the cell cycle, and by stimulating cell death via apoptosis.

It is likely that other phytochemical classes also contribute to the growth inhibitory properties of these extracts. Our qualitative phytochemical screening studies indicate that polyphenolics, flavonoids, saponins, and tannins were present in the methanolic and aqueous T. carpentariae and T. grandiflora extracts. However, no compounds of these classes were identified by GC-MS analysis. As GC-MS techniques generally only detect lower polarity compounds, many mid to higher polarity bioactive 
compounds may have been missed. Recent studies have reported the LC-MS profiles of extracts prepared from other Australian Terminalia spp. ${ }^{21,50}$ Several features were common to all of these studies. In particular, all of these studies reported on the high levels of a diversity of tannins in the Terminalia extracts. Recent studies have also highlighted the stilbene components in extracts prepared from different Australian Terminalia spp. ${ }^{12,50}$ Resveratrol and the glycosylated resveratrol derivative piceid, and several combretastatins were putatively identified in those studies. Stilbenes have attracted much recent interest due to their reported potent ability to block cancer cell progression and induce apoptosis by binding intracellular tubulin, thereby disrupting microtubule formation $^{51}$ Further studies utilising LC-MS are required to identify the mid to higher polarity compounds in the methanolic T. carpentariae and $T$. grandiflora extracts for a more complete understanding of the complete plant metabolome.

Whilst the use of high levels of antioxidants may be an attractive option in the prevention and treatment some cancers, oxidative stress is not the sole factor in the development and progression of cancer. Genetic factors, dietary habits and environmental factors may all contribute to cancer development. Furthermore, even in oxidative stress induced cancers, dietary antioxidants are of limited value as it is difficult to supply enough of the beneficial antioxidants directly in the food to function effectively as chemo-protectants and/or chemo-therapeutics. Instead, high antioxidant extracts may be required to obtain a high enough dosage to be effective. Despite this, numerous studies have reported the beneficial effects of using high levels of phytochemical antioxidants in cancer prevention and treatment and the T. carpentariae and T. grandiflora extracts examined in this report may also prove to be useful anticancer agents.

The findings reported here also demonstrate that the majority of the fruit and leaf extracts were nontoxic towards Artemia franciscana nauplii. Of the extracts tested, only the methanolic T. grandiflora extracts displayed $\mathrm{LC}_{50}$ values $<1000 \mu \mathrm{g} / \mathrm{mL}$. Notably, these extracts were determined to have relatively high antioxidant capacities (Table 1). The high antioxidant levels in similar extracts prepared from other Terminalia spp. is due to high ascorbic acid levels. ${ }^{18}$ As Artemia nauplii are susceptible to $\mathrm{pH}$ changes and to high ascorbic acid content, ${ }^{23,24,31}$ it is possible the mortality induced by these extracts is due to the high levels of ascorbic acid. All other extracts examined in this study were nontoxic, although further studies using human cell lines are required to verify the safety of these extracts for therapeutic use.

\section{CONCLUSION}

The results of this study demonstrate the potential of $T$. carpentariae and T. grandiflora extracts to inhibit Caco-2 and HeLa cell proliferation. The low level of toxicity of the extracts further indicates their potential as cancer chemotherapeutics. However, caution is needed before these compounds can be applied to medicinal purposes. In particular, further toxicity studies using human cell lines are needed to verify the suitability of these extracts for these purposes. Furthermore, purification and identification of the bioactive components is needed to examine the mechanisms of action of these agents.

\section{ACKNOWLEDGEMENT}

The authors are grateful to David Boehme of Wild Harvest, Northern Territory, Australia and to the Groote Esylandt Aboriginal elders for providing the plant material used in this study. Financial support for this work was provided by the Environmental Futures Research Institute and the School of Natural Sciences, Griffith University, Australia.

\section{CONFLICT OF INTEREST}

Nil

\section{ABBREVIATIONS USED}

DMSO: Dimethyl sulfoxide; $\mathbf{I C}_{50}$ : The concentration required to achieve $50 \%$ effect; $\mathbf{L C}_{50}$ : The concentration required to achieve $50 \%$ mortality.

\section{REFERENCES}

1. Halliwell B. Vitamin C: Antioxidant or pro-oxidant in vivo? Free Radical Research. 1996;25(5):439-54. https://doi.org/10.3109/10715769609149066 PMid:8902542

2. Kumagai $S$, Nobuhara $Y$, Saegusa J. Oxidative stress and autoimmune diseases. Nippon Naika Gakkai Zasshi. 2003;92:1096-103. https://doi.org/10.2169/ naika.92.1096; PMid:12866460

3. Brown NS, Bicknell R. Hypoxia and oxidative stress in breast cancer. Oxidative stress: its effects on the growth, metastatic potential and response to therapy of breast cancer. Breast Cancer Research. 2001;3(5):323-7. https://doi. org/10.1186/bcr315; PMCid:PMC138696.

4. Tome ME, Baker AF, Powis G, Payne CM, Briehl MM. Catalase-overexpressing thymocytes are resistant to glucocorticoid-induced apoptosis and exhibit increased net tumor growth. Cancer Research. 2001;61(6):2766-73. PMid:11289160

5. Florea AM, Büsselberg D. Cisplatin as an anti-tumor drug: cellular mechanisms of activity, drug resistance and induced side effects. Cancers. 2011;3(1):1351-71. https://doi.org/10.3390/cancers3011351; PMid:24212665 PMCid:PMC3756417.

6. Sitzia J, Huggins L. Side effects of cyclophosphamide, methotrexate, and 5-fluorouracil (CMF) chemotherapy for breast cancer. Cancer Practice 1998;6(1):1321. https://doi.org/10.1046/j.1523-5394.1998.1998006013.x ; PMid:9460322.

7. Zahreddine $H$, Borden KLB. Mechanisms and insights into drug resistance in cancer. Frontiers in Pharmacology. 2013:4:28. https://doi.org/10.3389/ fphar.2013.00028; PMid:23504227 PMCid:PMC3596793.

8. Gottesman MM. Mechanisms of cancer drug-resistance. Annual Reviews in Medicine. 2002;53(1):615-27. https://doi.org/10.1146/annurev. med.53.082901.103929; PMid:11818492.

9. Jamieson N, Sirdaarta J, Cock IE. The anti-proliferative properties of Australian plants with high antioxidant capacities against cancer cell lines. Pharmacognosy Communications 2014;4(4):71-82.

10. Cock IE. Problems of reproducibility and efficacy of bioassays using crude extracts, with reference to Aloe vera. Pharmacognosy Communications. 2011;1(1):52-62. DOI: 10.5530/pc.2011.1.3. https://doi.org/10.5530/pc.2011.1.3.

11. Mohanty S, Cock IE. The chemotherapeutic potential of Terminalia ferdinandiana: Phytochemistry and bioactivity. Pharmacognosy Reviews. 2012;6(1):29-36. DOI: 10.4103/0973-7847.95855. https://doi.org/10.4103/0973-7847.95855.

12. Cock IE. The medicinal properties and phytochemistry of plants of the genus Terminalia (Combretaceae). Inflammopharmacology. 2015;23(5);203-29. DOI: 10.1007/s10787-015-0246-z. https://doi.org/10.1007/s10787-015-0246-z.

13. Sandhya T, Lathika KM, Pandey BN, Mishra KP. Potential of traditional Ayurvedic formulation, triphala, as a novel anticancer drug. Cancer Letters. 2006;231:20614. https://doi.org/10.1016/j.canlet.2005.01.035; PMid:15899544.

14. Kaur S, Michael H, Arora S, Härkönen PL, Kumar S. The in vitro cytotoxic and apoptotic activity of Triphala: An Indian herbal drug. Journal of Ethnopharmacology. 2005;97:15-20.https://doi.org/10.1016/j.jep.2004.09.050 ; PMid:15652269.

15. Shi Y, Sahu RP, Srivastava SK. Triphala inhibits both in vitro and in vivo xenograft growth of pancreatic tumor cells by inducing apoptosis. BMC Cancer 2008;8(1):294. https://doi.org/10.1186/1471-2407-8-294 ; PMid:18847491 PMCid:PMC2576337.

16. Sandhya T, Mishra KP. Cytotoxic response of breast cancer cell lines, MCF7 and T $47 \mathrm{D}$ to triphala and its modification by antioxidants. Cancer Letters. 2006;238(2):304-13. https://doi.org/10.1016/j.canlet.2005.07.013 PMid:16135398

17. Pinmai K, Chunlaratthanabhorn S, Ngamkitidechakul C, Soonthornchareon N, Hahnvajanawong C. Synergistic growth inhibitory effects of Phyllanthus em blica and Terminalia bellerica extracts with conventional cytotoxic agents: Doxorubicin and cisplatin against human hepatocellular carcinoma and lung cancer cells. World Journal of Gastroenterology. 2008;14(10):1491-7. https://doi. org/10.3748/wjg.14.1491; PMid:18330936 PMCid:PMC2693740.

18. Netzel M, Netzel G, Tian Q, Schwartz S, Konczak I. Native Australian fruits - a novel source of antioxidants for food. Innovative Food Science and Emerging Technologies. 2007;8(3):339-46. https://doi.org/10.1016/j.ifset.2007.03.007.

19. Tan AC, Konczak I, Ramzan I, Sze DMY. Potential antioxidant, antiinflammatory, and proapoptotic anticancer activities of Kakadu plum and Illawarra plum polyphenolic fractions. Nutrition and Cancer. 2011;63(7):1074-84. https://doi.org/10. 1080/01635581.2011.596646; PMid:21875324.

20. Boyer $\mathrm{H}$, Cock IE. Evaluation of the potential of Macadamia integriflora extracts as antibacterial food agents. Pharmacognosy Communications. 2013;3(3);53- 
62. DOI: $10.5530 / p c .2013 .3 .10$

21. Sirdaarta J, Matthews B, White A, Cock IE. GC-MS and LC-MS analysis of Kakadu plum fruit extracts displaying inhibitory activity against microbial triggers of multiple sclerosis. Pharmacognosy Communications. 2015;5(2):100-15. DOI: 10.5530/pc.2015.2.2. https://doi.org/10.5530/pc.2015.2.2

22. Arkhipov A, Sirdaarta J, Rayan P, McDonnell PA, Cock IE. An examination of the antibacterial, antifungal, anti-Giardial and anticancer properties of Kigelia africana fruit extracts. Pharmacognosy Communications. 2014;4(3):62-76. DOI: 10.5530/pc.2014.3.7. https://doi.org/10.5530/pc.2014.3.7.

23. Ruebhart DR, Wickramasinghe W, Cock IE. Protective efficacy of the antioxidants vitamin $\mathrm{E}$ and Trolox against Microcystis aeruginosa and microcystin-LR in Artemia franciscana nauplii. Journal of Toxicology and Environmental Health Part A. 2009;72(24):1567-75. https://doi.org/10.1080/15287390903232459 PMid:20077231

24. Cock IE, Ruebhart, DR. Assessment of the toxicity of selected Australian native plant extracts using the Artemia franciscana nauplii bioassay. The Internet Journal of Toxicology 2008;5:2

25. Zhang W, Men X, Lei P. Review on anti-tumor effect of triterpene acid compounds. Journal of Cancer Research and Therapeutics 2014;10(5):14-9. https:// doi.org/10.4103/0973-1482.139746; PMid:25207885

26. Bishayee A, Ahmed S, Brankov A, Perloff M. triterpenoids as potential agents for the chemoprevention and therapy of breast cancer. Frontiers in Bioscience. 2011;16:980-96. https://doi.org/10.2741/3730.

27. Potter JD. Cancer prevention: Epidemiology and experiment. Cancer Letters. 1997;114(1-2)7-9. https://doi.org/10.1016/S0304-3835(97)04615-6.

28. Hertog MG, Bueno-de-Mesquita HB, Fehily AM, Sweetnam PM, Elwood PC, Kromhout D. Fruit and vegetable consumption and cancer mortality in the caerphilly study. Cancer Epidemiology, Biomarkers and Prevention. 1996;5(9):673-7. PMid:8877056.

29. Coșkun Ş, Gönül B, Güzel NA, Balabanli B. The effects of vitamin C supplementation on oxidative stress and antioxidant content in the brains of chronically exercised rats. Molecular and Cellular Biochemistry. 2005;280(1):135-8. https:// doi.org/10.1007/s11010-005-8421-y ; PMid:16311914

30. Tafazoli S, Wright JS, O'Brien PJ. Prooxidant and antioxidant activity of vitamin E analogues and troglitazone. Chemical Research in Toxicology. 2005;18(10):156774. https://doi.org/10.1021/tx0500575 ; PMid:16533021.

31. Sirdaarta J, Cock IE. Vitamin E and TroloxTM reduce toxicity of Aloe barbadensis Miller juice in Artemia franciscana nauplii but individually are toxic at high concentrations. The Internet Journal of Toxicology 2008;5:(1)

32. Driver C, Georgeou A. Variable effects of vitamin $E$ on Drosophilia longevity. Biogerontology. 2003;4(2):91-5. https://doi.org/10.1023/A:1023347803932 PMid:12766533.

33. Miller ER, Pastor-Barriuso R, Dalal D, Riemersma RA. 2005. Meta-analysis: high dosage vitamin $\mathrm{E}$ supplementation may increase all-cause mortality. Annals of Internal Medicine. 142(1):37-46. https://doi.org/10.7326/0003-4819-142-1 $200501040-00110$; PMid:15537682.

34. Sohal RS, Arnold L, Orr WC. Effect of age on superoxide dismutase, catalase, glutathione reductase, inorganic peroxides, TBA-reactive material, GSH/GSSG, $\mathrm{NADPH} / \mathrm{NADP}+$ and NADH/NAD+ in Drosophila melanogaster. Mechanisms of Ageing and Development 1990;56(3):223-5. https://doi.org/10.1016/00476374(90)90084-S.

35. Allen RG, Venkatraj VS. 1992. Oxidants and antioxidants in development and differentiation. Journal of Nutrition. 1992;122(3S):631-5. PMid:1542023.

36. Yang GY, Wang ZY, Kim S, Liao J, Seril DN, Chen X, Smith TJ, Yang CS. Characterization of early pulmonary hyperproliferation, tumor progression and inhibition by black tea in a 4- (methylnitrosamino)-1-(3-pyridyl)-1-butanone (NNK)-induced

\section{PICTORIAL ABSTRACT}

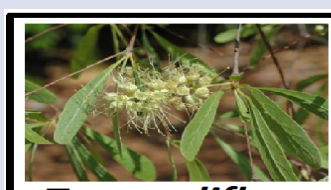

T. grandiflora

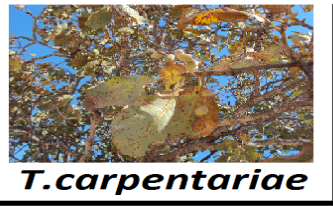

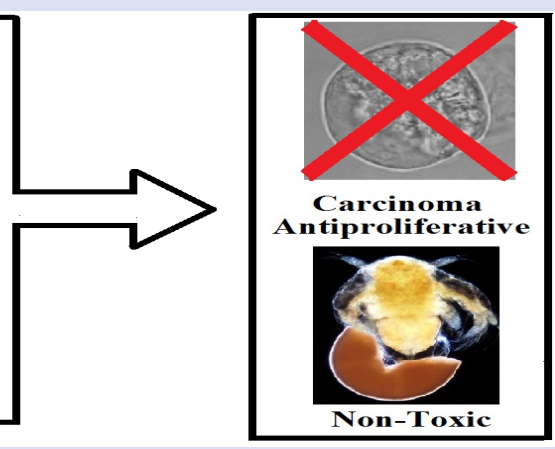

lung tumorigenesis model with A/J mice. Cancer Research. 1997;57(10):1889 94. PMid:9157981.

37. Burdon $\mathrm{RH}$. Superoxide and hydrogen peroxide in relation to mammalian cell proliferation. Free Radical Biology and Medicine 1995;18(4):775-94. https://doi. org/10.1016/0891-5849(94)00198-S.

38. Alaluf S, Muir-Howie H, Hu HL, Evans A, Green MR. Atmospheric oxygen accelerates the induction of a post-mitotic phenotype in human dermal fibroblasts: the key protective role of glutathione. Differentiation. 2000;66(2):147-55. https://doi.org/10.1046/j.1432-0436.2000.660209.x ; PMid:11100905.

39. Eberhardt, MV, Lee CY, Liu RH. Nutrition: Antioxidant activity of fresh apples Nature. 2000:405(6789):903-4. https://doi.org/10.1038/35016148 : https://doi. org/10.1038/35016151; PMid:10879522

40. Chen AY, Chen YC. A review of the dietary flavonoid, kaempferol on human health and cancer prevention. Food Chemistry. 2013;138(4):2099-107. https:// doi.org/10.1016/j.foodchem.2012.11.139; PMid:23497863 PMCid:PMC3601579.

41. Lin KW, Huang AM, Lin CC, Chang CC, Hsu WC, Hour TC, Pu YS, Lin CN. Anticancer effects of ursane triterpenoid as a single agent and in combination with cisplatin in bladder cancer. Molecular and Cellular Pharmacology. 2014;740:74251. https://doi.org/10.1016/j.ejphar.2014.05.051.

42. Es-Saady D, Simon A, Jayat-Vignoles C, Chulia AJ, Delage C. MCF-7 cell cycle arrested at G1 through ursolic acid, and increased reduction of tetrazolium salts. Anticancer Research. 1996;16(1):481-6. PMid:8615658.

43. Neto CC, Vaisberg AJ, Zhou B-N, Kingston DGI, Hammond GB. Cytotoxic triterpene acids from the Peruvian medicinal plant Polylepis racemosa. Planta Medica. 2000;66(05):483-4. https://doi.org/10.1055/s-2000-8583 ; PMid:10909276.

44. Subbaramaiah K, Michaluart P, Sporn MB, Dannenberg AJ. Ursolic acid inhibits cyclooxygenase-2 transcription in human mammary epithelial cells. Cancer Research. 2000;60(9):2399-404. PMid:10811116.

45. Konopleva M, Zhang W, Shi Y, McQueen T, Tsao T, Abdelrahim M, Munsell MF Johansen M, Yu D, Hung M, Andreeff M. Synthetic triterpenoid 2-cyano-3,12-dioxooleana-1,9-dien-28-oic acid induces growth arrest in HER2-over expressing breast cancer cells. Molecular Cancer Therapeutics. 2006;5(2):317-28. https:// doi.org/10.1158/1535-7163.MCT-05-0350 ; PMid:16505105.

46. Nomura M, Takahashi T, Uesugi A, Tanaka R, Kobayashi S. Inotodiol, a lanostane triterpenoid, from Inonutus obliquus inhibits cell proliferation through caspase-3-dependent apoptosis. Anticancer Research. 2008;28(5A):2691-6. PMid:19035296.

47. Jiang J, Grieb B, Thyagarajan A, Sliva D. 2008. Ganoderic acids suppress growth and invasive behavior of breast cancer cells by modulating Ap-1 and Nf-Kappa B signaling. International Journal of Molecular Medicine. 1;21(5):577.

48. Mizushina Y, Akihisa T, Ukiya M, Murakami C, Kuriyama I, Xu X, Yoshida H, Sakaguchi K. 2004. A novel DNA topoisomerase inhibitor: dehydroebriconic acid, one of the lanostane-type triterpene acids from Poria cocos. Cancer Science. 2004;95(4):354-60. https://doi.org/10.1111/j.1349-7006.2004.tb03215.x.

49. Wright MH, Sirdaarta J, White A, Greene AC, Cock IE. Bacillus anthracis growth inhibitory properties of Australian Terminalia spp.: Putative identification of low polarity volatile components by GC-MS headspace analysis. Pharmacognosy Journal. 2016;8(3):281-90. DOI: 10.5530/pj.2016.3.18. https://doi.org/10.5530/ pj.2016.3.18.

50. Wright MH, Sirdaarta J, Matthews B, Greene AC, Cock IE. Growth inhibitory activity of Kakadu plum extracts against the opportunistic pathogen Clostridium perfringens: New leads in the prevention and treatment of clostridial myonecrosis. Pharmacognosy Journal. 2016;8(2):144-53. DOI: 10.5530/pj.2016.2.8 https://doi.org/10.5530/pj.2016.2.8.

51. Dark GG, Hill SA, Prise VE, Tozer GM, Pettit GR, Chaplin DJ. Combretastatin A-4 an agent that displays potent and selective toxicity towards tumor vasculature. Cancer Research. 1997;57(10):1829-34. PMid:9157969.

\section{SUMMARY}

- T. carpentariae and T. grandiflora extracts displayed potent antiproliferative activity against Caco-2 and HeLa carcinoma cells.

- The methanolic T. grandiflora leaf extract was particularly effective against Caco- 2 cells $\left(\mathrm{IC}_{50}=372 \mu \mathrm{g} / \mathrm{mL}\right)$.

- The methanol T. carpentariae $\left(\mathrm{IC}_{50}=864 \mu \mathrm{g} / \mathrm{mL}\right)$ and T. grandiflora leaf extracts $\left(\mathrm{IC}_{50}=833 \mu \mathrm{g} / \mathrm{mL}\right)$ were also potent inhibitors of HeLa cell proliferation.

- The methanolic T. grandiflora fruit and nut extracts and all aqueous and ethyl acetate extracts, were moderate to good inhibitors of carcinoma proliferation.

- All T. carpentariae and T. grandiflora extracts were non-toxic or of low toxicity in the Artemia nauplii assay.

- Three lanostane and 2 pentacyclic triterpenoids were identified in the methanolic T. grandiflora leaf extract 


\section{ABOUT AUTHOR}

Dr lan Cock leads a research team in the Environmental Futures Research Institute and the School of Natural Sciences at Griffith University, Australia. His research involves bioactivity and phytochemical studies into a variety of plant species of both Australian and international origin, including Aloe vera, South Asian and South American tropical fruits, as well as Australia plants including Scaevola spinescens, Pittosporum phylliraeoides, Terminalia ferdinandiana (Kakadu plum), Australian Acacias, Syzygiums, Petalostigmas and Xanthorrhoea johnsonii (grass trees). This range of projects has resulted in nearly 200 publications in a variety of peer reviewed journals.

Cite this Article: Courtney R, Sirdaarta J, White A, Cock IE. Inhibition of Caco-2 and HeLa proliferation by Terminalia carpentariae C. T. White and Terminalia grandiflora Benth. extracts: Identification of triterpenoid components. Pharmacogn J. 2017;9(4):441-51. 